\title{
Evaluation of the effect of reinforcement particle sizes on the impact and hardness properties of hardwood charcoal particulate-polyester resin composites
}

\author{
R.O. Akaluzia ${ }^{a}$, F.O. Edoziuno ${ }^{\mathrm{a}, \mathrm{b}, *}$, A.A. Adediran ${ }^{\mathrm{c}, \mathrm{d}}$, B.U. Odoni ${ }^{\mathrm{a}}$, S. Edibo ${ }^{\mathrm{a}}$, T.M.A. Olayanju ${ }^{\mathrm{d}}$ \\ ${ }^{a}$ Department of Metallurgical Engineering, Delta State Polytechnic, P.M.B. 1030 Ogwashi-Uku, Nigeria \\ ${ }^{\mathrm{b}}$ Department of Metallurgical \& Materials Engineering, Nnamdi Azikiwe University, P.M.B. 5025 Awka, Nigeria \\ c Department of Mechanical Engineering, Landmark University, P.M.B. 1001, Omu-Aran, Kwara State, Nigeria \\ ${ }^{\mathrm{d}}$ Landmark University Waste to Wealth and Energy Initiative Group, P.M.B. 1001, Omu-Aran, Kwara State, Nigeria
}

\section{A R T I C L E I N F O}

\section{Article history:}

Received 14 January 2020

Received in revised form 26 February 2020

Accepted 29 February 2020

Available online $\mathrm{xxxx}$

\section{Keywords:}

Hardwood charcoal

Impact energy

Hardness

Polymer matrix composite

Particulate reinforcements

\begin{abstract}
A B S T R A C T
The influence of hardwood charcoal particles (HWCP) on some mechanical properties and surface morphology of polyester matrix composites (PMC) was investigated in this work. The polyester base matrix was reinforced with varying weight fraction of HWCP. The composites developed were subjected to impact and hardness tests respectively. The morphological characteristics, elemental characterization and quantification of the synthesized composites were also evaluated. From the results, it is revealed that the composites reinforced with the largest particle sized hardwood charcoal ( $300 \mu \mathrm{m})$ absorbed high impact energy before fracture. However, the composites with lower particle sizes (75, $150 \& 250 \mu \mathrm{m})$ recorded a high hardness values with increasing weight percent of reinforcements incorporated in the polyester matrix composite. These higher values obtained were attributable to better interfacial bonding due to better mechanical interlocking between the HWCP and polyester resin. The EDX results indicated an increase in the contents of calcium, silicon, potassium and aluminium in the reinforced polyester matrix composites. SEM image show the homogeneous distribution of the reinforcement particles in the majorly carbon matrix phase and increased surface roughness of the reinforced polyester matrix composites.

(c) 2020 Elsevier Ltd. All rights reserved.

Selection and peer-review under responsibility of the scientific committee of the International Symposium on Nanostructured, Nanoengineered and Advanced Materials. This is an open access article under the CC BY-NC-ND license (http://creativecommons.org/licenses/by-nc-nd/4.0/).
\end{abstract}

\section{Introduction}

Composite materials are fabricated by physical combination/ mixture of two or more materials that result in a component with superior properties to those of the individual components [1-3]. In contrast to chemically combined metallic alloys, each material retains its distinct chemical, physical, and mechanical properties $[4,5]$. The main advantages of composite materials are their high specific strength and stiffness, when compared with other materials allowing for a final weight reduction in finished products $[1,6]$. Composites may be classified based on the reinforcements' physical morphology as particulate reinforced composites or fiber rein-

\footnotetext{
* Corresponding author at: Department of Metallurgical Engineering, Delta State Polytechnic, P.M.B. 1030 Ogwashi-Uku, Nigeria.

E-mail addresses: francisedoziuno@gmail.com, dladesoji@gmail.com (F.O. Edoziuno).
}

forced composites [6]. The particulate reinforced composites consist of tiny particles having their reinforcements dimensions in the micron $(\mu \mathrm{m})$ and nanoscales $(\mathrm{nm})$ ranges [7] embedded into a matrix. The particles may physically occur in the form of flakes or powder [8]. Fiber reinforced composites on the other hand are made of continuous or discontinuous strands of reinforcing fibers. Composites materials can as well be classified based on the matrix materials, as metal matrix composites (MMC), ceramic matrix composites (CMC), and polymer matrix composites (PMC). Examples of matrix materials for PMC include epoxy resins, polyester resins, and phenolic resins, etc., while metallic matrices include aluminium, magnesium, copper, and titanium and their alloys [6]. The constituents of a composite are categorized as the reinforcement phase and the matrix phase. The reinforcement is the discontinuous phase while the matrix is the continuous phase $[5,6]$. The reinforcement is usually embedded in the matrix. The reinforcement may be in the form of fibers, sheets, or particles 
whereas the matrix is either a polymer, ceramic, or metals and their alloys $[1,6]$. The reinforcement provides strength and stiffness to the composite material. In polymer and metal matrix composites, the matrix transmits loads from the matrix to the fibers through shear loading at the interface, and in many cases contributes some other properties required, such as ductility, toughness, and electrical insulation $[1,2,6]$. Polymers have low strength and stiffness, metals have intermediate strength and stiffness but high ductility, and ceramics have high strength and stiffness but are brittle. The matrix (continuous phase) performs several other critical functions, such as maintaining the fibers in the proper orientation and spacing, and protecting them from abrasion and the environment $[1,2]$. The most common methods used in the manufacture of composite materials are compression moulding, pultrusion, hand layup, resin transfer moulding (RTM), injection moulding, and filament moulding [1,2,8,9]. Growing interest has risen in the use of natural fiber reinforced composites among researchers [10]. Natural fibers are increasingly being considered as an environmentally friendly substitute for synthetic fibers in the reinforcement of polymer matrix composites [10,11]. Natural fiber or particulate reinforced polymer matrix composites are widely used because of their advantageous properties like minimum density, maximum specific strength, low cost and availability which had made them find wide range of applications [7,8,12-14]. The source of the natural fibers or particulates can be plants, animals, and minerals $[8,9,12]$. Impact strength is the ability of a material to resist fracture due to sudden impact [7]. Impact tests are usually carried out during the earliest stages of the design process in order to determine the integrity of the material under impact loading. Impact tests are usually done in order to determine the maximum impact load that a material can absorb at a particular temperature. Impact resistance of fiber and particulatereinforced composites, like that of other materials, is measured by several techniques, such as, Charpy, Izod, drop weight, split Hopkinson bar (SHB), explosive, and ballistic impact. The results of impact tests are presented in the form of fracture energy, damage accumulation, and/or measurement of the number of drops to achieve a determined damage or stress level. Impact test results depend on many variables such as size of specimen, strain rate, type of instrumentation, and test setup. Hardness on the other hand, refers to the resistance a solid material show to indentation or local deformation forces [7]. During a hardness test, a hard indenter is placed onto the surface of a material and is then pressed into the material. The size of the permanent indentation thus obtained is then measured to determine the hardness of the material. Common test methods for the determination of hardness of materials are the Brinell hardness test, Rockwell hardness test, Vickers hardness test, and the Barcol hardness test. Unlike the Brinell, Rockwell, and Vickers hardness test methods that are used widely, the Barcol hardness test is rarely performed. Charcoal is the chief product of wood pyrolysis and may provide an alternative option to partly replace conventional fillers due to its relatively low cost and high availability [15]. It is an abundant, environmentally friendly, low-cost, and renewable bio-resource on earth. The wood and wood residues can be transformed to charcoal at a high temperature in the absence of oxygen. The characteristics of charcoal depend on not only the type of wood used, but also the system of carbonization [15]. If the charcoal was carbonized under high temperature (above $700{ }^{\circ} \mathrm{C}$ ), it will make a good conductive material and can as well absorb electromagnetic wave. It also possesses many advantages, such as supplier of negative ions, emitting infrared rays, humidity regulator, oxidization prevention, and a rich source of natural minerals [15]. However, many researchers have studied charcoal as an adsorbent and there is little research on its use to improve the mechanical properties of charcoal-polymer composites. Polyester resin have lower cost than epoxy resin, but they exhibit generally, lower temperature capability, lower mechanical properties and inferior weathering resistance. The present study is designed to investigate the influence of four different particle sizes of hardwood charcoal on the impact strength, hardness and structure of polyester matrix composite. The addition of hardwood charcoal particles as reinforcement in polyester matrix is intended to further reduce the cost and at the same time enhance the mechanical properties. This could lead to the development of polymer composite material that would find applications in areas where high mechanical strength combination with low weight, good corrosion resistance, biodegrability and cost are generally required; such as in aerospace, electrical and electronics components, and as ecofriendly composite material for the exterior and interior automobile components.

\section{Experimental procedure}

\subsection{Materials}

Polyester resin was obtained from a local chemical vendor at Lagos, while catalyst and accelerator (methyl-ethyl ketone peroxide and cobalt naphthanate) were obtained from Local chemical vendor at Ibadan, Nigeria. Hardwood charcoal pellets were obtained from Abraka Market, Asaba, Delta State, Nigeria.

\subsection{Preparation of the reinforcement}

The lumps of hardwood charcoal was milled using a milling machine and the particle size classification was carried out using standardized sieves mounted on a motorized sieve shaker to obtain fine powders of various sieve sizes $(75,150,250 \& 300 \mu \mathrm{m})$ used in this investigation.

\subsection{Manufacture of composites}

In developing the reinforced polyester composites, the volume of the polyester resin was varied with that of the reinforcements to give a total composite volume of $98.21 \mathrm{~cm}^{3}$ for each sample. The required materials were weighed using graduated glass cylinder and an electronic weighing balance. Weighed amount of the polyester matrix was placed in a $200 \mathrm{ml}$ glass beaker and measured quantities (5-30 wt\% in the interval of $5 \mathrm{wt} \%$ ) of the hardwood charcoal reinforcement were added to the polyester matrix and stirred thoroughly for $10 \mathrm{~min}$ using a long glass rod to avoid clustering and achieve accelerated and homogeneous distribution of the reinforcement particles in the matrix. Thereafter, catalyst was added with the help of disposable syringe at the ratio of $10 \mathrm{ml}$ of polyester to $0.2 \mathrm{ml}$ of catalyst and stirred for about two minutes, after which, accelerator was also added in the proportion of $10 \mathrm{ml}$ of polyester to $0.1 \mathrm{ml}$ of accelerator and stirred for about two minutes. The composite slurry was steadily poured into the prepared wooden moulds coated with petroleum jelly as mould release agent for various test specimens and allowed to cure for $24 \mathrm{~h}$ after which they were removed from the moulds. Six different weight fractions $(5,10,15,20,25 \& 30 \mathrm{wt} \%)$ of the reinforcements were used with four different particle sizes of the reinforcements (75, 150, 250 and $300 \mu \mathrm{m}$ of charcoal particles). Twenty four composites compositions were developed. The sample containing only polyester matrix was also produced and used as the control for comparison. Three test specimens were produced from the developed composites each for the impact and hardness tests, and the average recorded. 


\subsection{Impact tests}

In order to determine the impact properties of the fabricated composites, Charpy impact tests were performed at room temperature using a Hounsfield balanced impact tester, which imposes a three-point impact similar to that created by the Charpy apparatus specified in ASTM D6110-10 [16]. Test specimens with a geometry of $75 \times 8 \times 3.5 \mathrm{~mm}$ in length, width, and thickness, respectively, were cut from the cast composites. For each composition, a Vnotch of $45^{\circ} \pm 1^{\circ}$, root radius of $0.25 \pm 0.05 \mathrm{~mm}$, and notch width of $2 \mathrm{~mm}$ was made. The specimens were, thereafter, sanded off using emery cloth of grade 220 in order to ensure that no out-of plane notches were introduced onto the specimens. The Charpy impact test, also known as the Charpy V-notch test, is a standardized high-strain rate test which is used to determine the amount of energy absorbed by a material during fracture.

\subsection{Hardness}

Hardness testing was done in accordance with ASTM E10 standard test specifications using the phase II model 900-355 Brinell hardness tester. Test specimens with a geometry of $10 \times 10 \times 10 \mathrm{~mm}$ in length, width, and thickness, respectively, were cut from the developed composites. The hardness test characterizes the indentation hardness of materials by measuring the depth of penetration of the indenter point. The testing cycle is automatically performed and involves; load application, load holding with dwell time counting down and unloading as soon as the dwell time is finished. The sample was mounted on the machine, and a testing load of $612.9 \mathrm{~N}$ was applied on it for a load dwell duration of about $10 \mathrm{~s}$ by an indenter ball of $5 \mathrm{~mm}$ diameter. The diameter of indentation left on the sample was measured with a low-powered 20X microscope in two perpendicular directions and inputted in the machine. The Brinell hardness value given in HBW unit is calculated automatically and displayed on the machine screen for reading. The HBW is converted to Brinell hardness number (BHN) unit by dividing with 0.102 .

\subsection{Scanning electron microscopy}

The surface morphologies of the composites of various particulate weight fractions were analyzed using electron microscopy technique. The composite surfaces were analyzed using Phenom Pro X Model SEM (Phenom world, Eindhoven, Netherlands) equipped with Energy Dispersive X-ray spectroscopy (EDX). The samples were analyzed at an accelerating voltage of $15 \mathrm{kV}$ at various magnifications (500, 1000 \& 1500X). The generated morphology is electronically transmitted to EDX coupled with elemental characterization software, which automatically identified the major, minor and trace elements in the sample and their concentrations in percentages. The reinforced and unreinforced polyester matrix were both scanned and examined.

\section{Results and discussion}

The results arising from the measurements of hardness and impact energy are presented in Table 1.

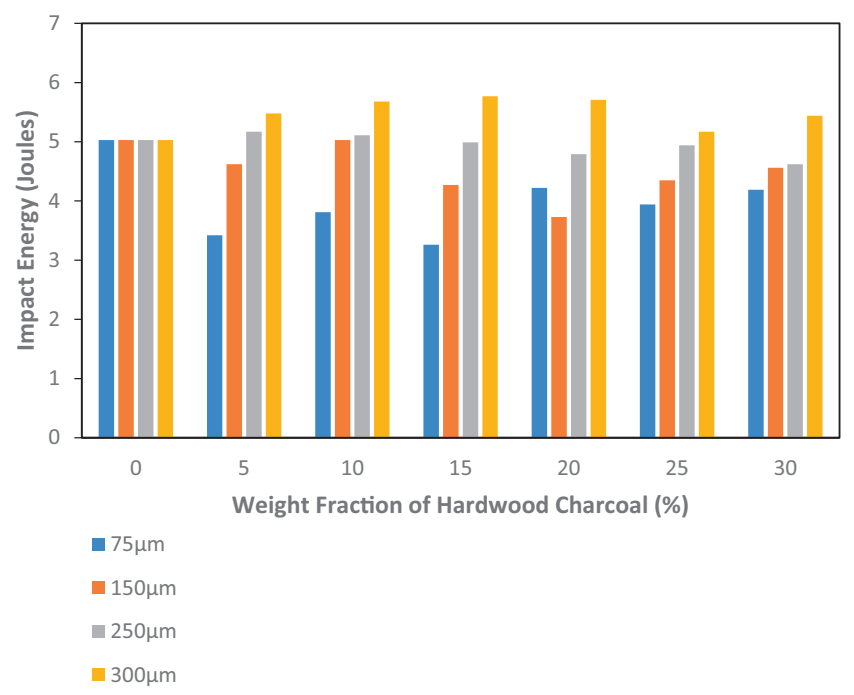

Fig. 1. A plot of the average values of impact energy versus particulate weight fraction (\%) of Hardwood-polyester resin matrix composites.

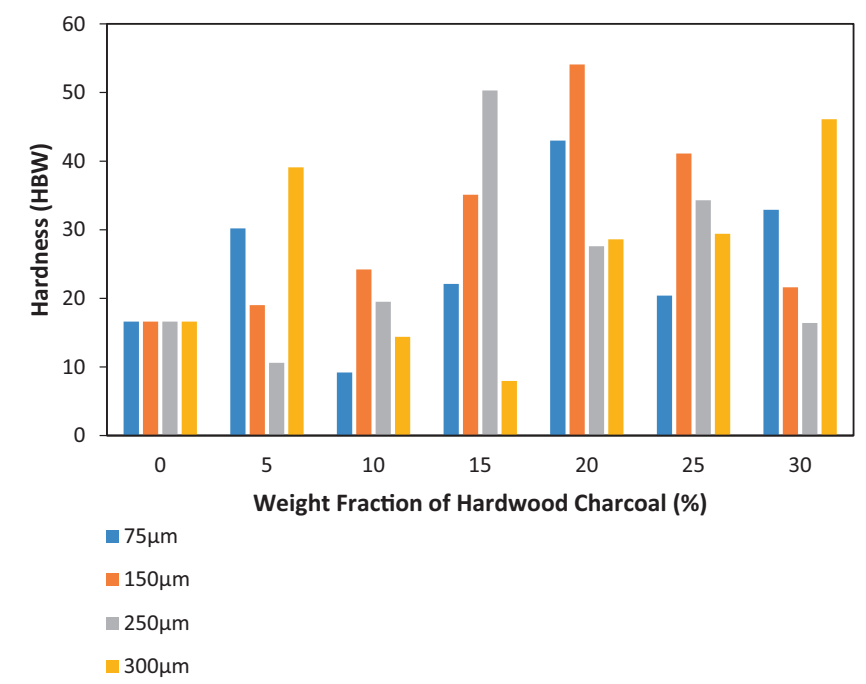

Fig. 2. A plot of the Hardness values (HBW) versus particulate weight fraction (\%) of Hardwood-polyester resin matrix composites.

Table 1

Hardness and impact properties for pure polyester resin and hardwood charcoal particulate reinforced polyester resin composites.

\begin{tabular}{|c|c|c|c|c|c|c|c|c|}
\hline \multirow[t]{2}{*}{ Reinforcement Weight Fraction (\%) } & \multicolumn{4}{|c|}{$\begin{array}{l}\text { Hardness Values of Hardwood Charcoal Reinforced } \\
\text { Polyester Resin Matrix Composites (HBW) }\end{array}$} & \multicolumn{4}{|c|}{$\begin{array}{l}\text { Impact Energy of Hardwood Charcoal Reinforced } \\
\text { Polyester Resin Matrix Composites (Joules) }\end{array}$} \\
\hline & $75 \mu \mathrm{m}$ & $150 \mu \mathrm{m}$ & $250 \mu \mathrm{m}$ & $300 \mu \mathrm{m}$ & $75 \mu \mathrm{m}$ & $150 \mu \mathrm{m}$ & $250 \mu \mathrm{m}$ & $300 \mu \mathrm{m}$ \\
\hline 0 & 16.6 & 16.6 & 16.6 & 16.6 & 5.03 & 5.03 & 5.03 & 5.03 \\
\hline 5 & 30.2 & 19.0 & 10.6 & 39.1 & 3.42 & 4.62 & 5.17 & 5.48 \\
\hline 10 & 9.19 & 24.2 & 19.5 & 14.4 & 3.81 & 5.03 & 5.11 & 5.68 \\
\hline 15 & 22.1 & 35.1 & 50.3 & 7.96 & 3.26 & 4.27 & 4.99 & 5.77 \\
\hline 20 & 43.0 & 54.1 & 27.6 & 28.6 & 4.22 & 3.73 & 4.79 & 5.71 \\
\hline 25 & 20.4 & 41.1 & 34.3 & 29.4 & 3.94 & 4.35 & 4.94 & 5.17 \\
\hline 30 & 32.9 & 21.6 & 16.4 & 46.1 & 4.19 & 4.56 & 4.62 & 5.44 \\
\hline
\end{tabular}

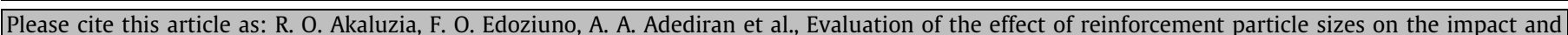

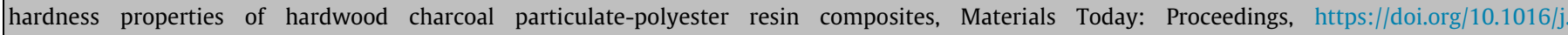



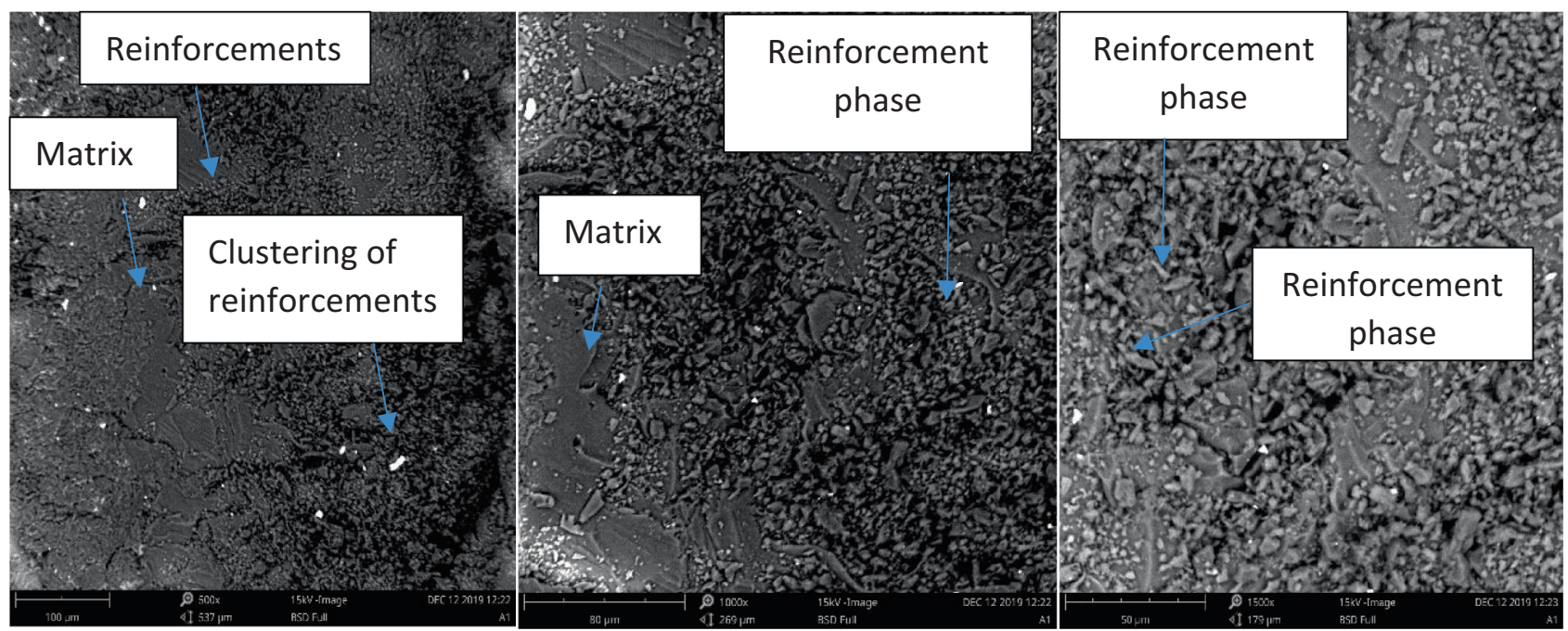

Fig. 3. SEM micrograph of $75 \mu \mathrm{m}$ and $5 \mathrm{wt} \%$ particulate charcoal reinforced polyester matrix composite scanned at different magnifications.

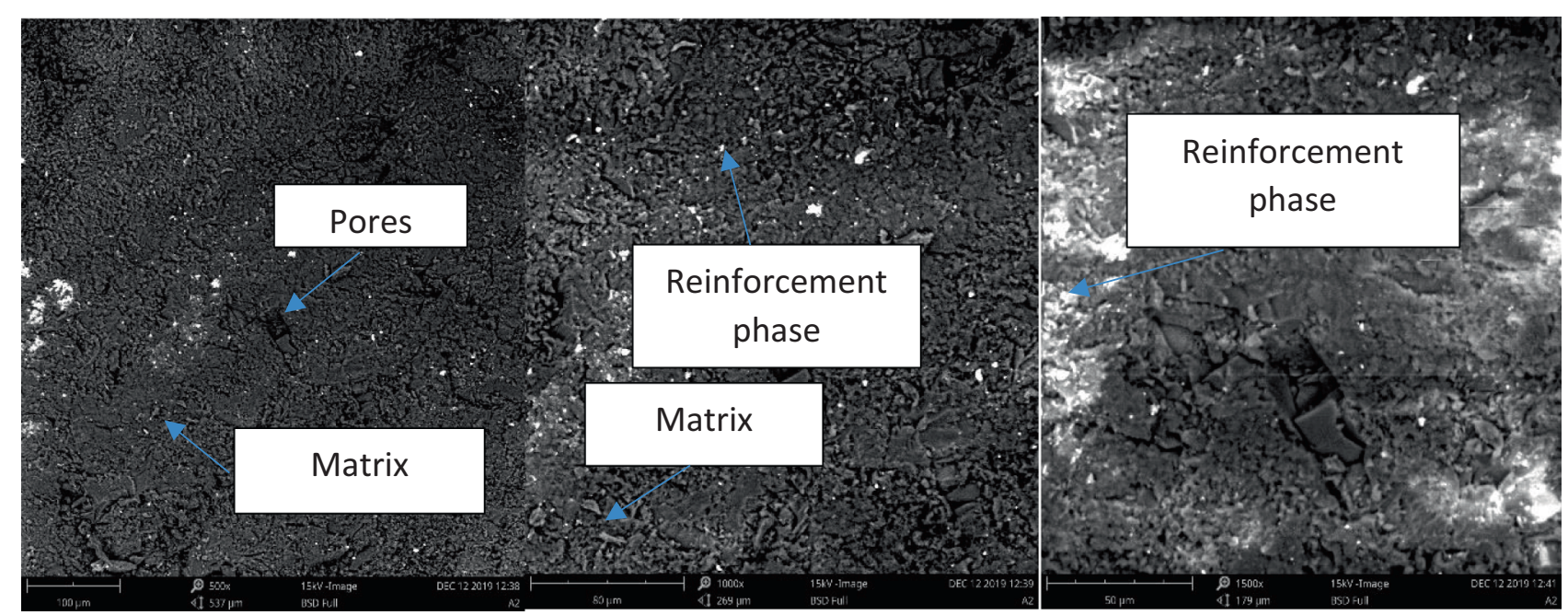

Fig. 4. SEM micrograph of $75 \mu \mathrm{m}$ and $10 \mathrm{wt} \%$ particulate charcoal reinforced polyester matrix composite scanned at different magnifications.

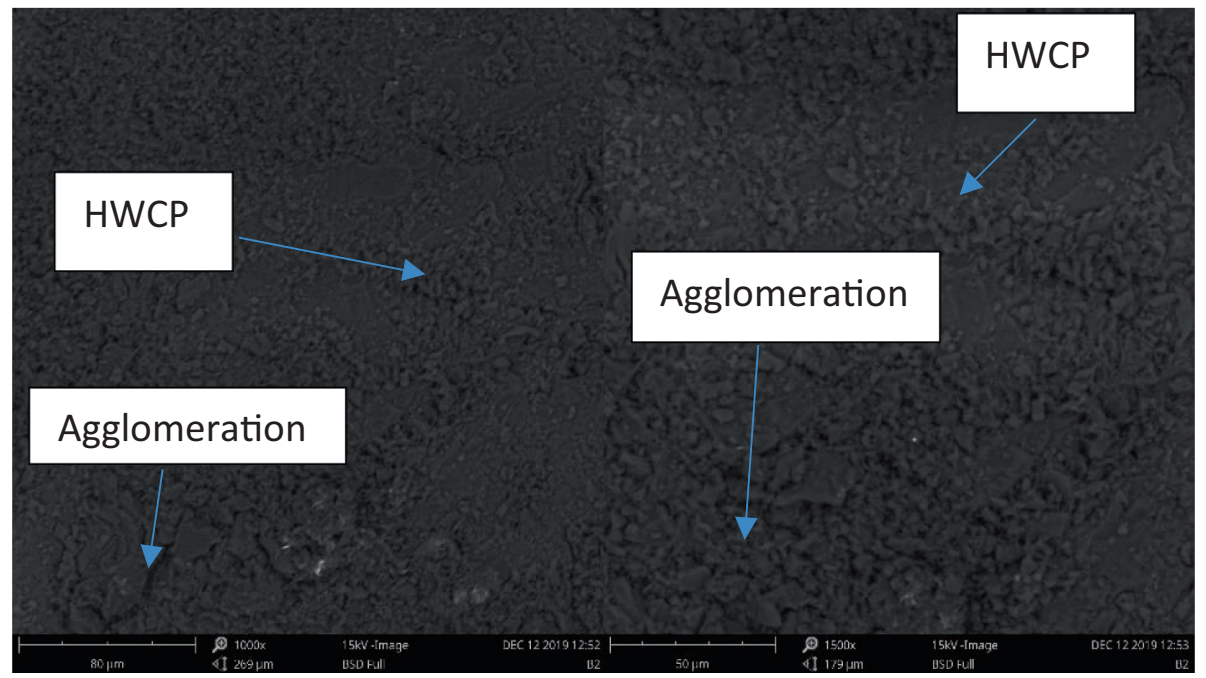

Fig. 5. SEM micrograph of $150 \mu \mathrm{m}$ and $10 \mathrm{wt} \%$ particulate charcoal reinforced polyester matrix composite scanned at different magnifications. 


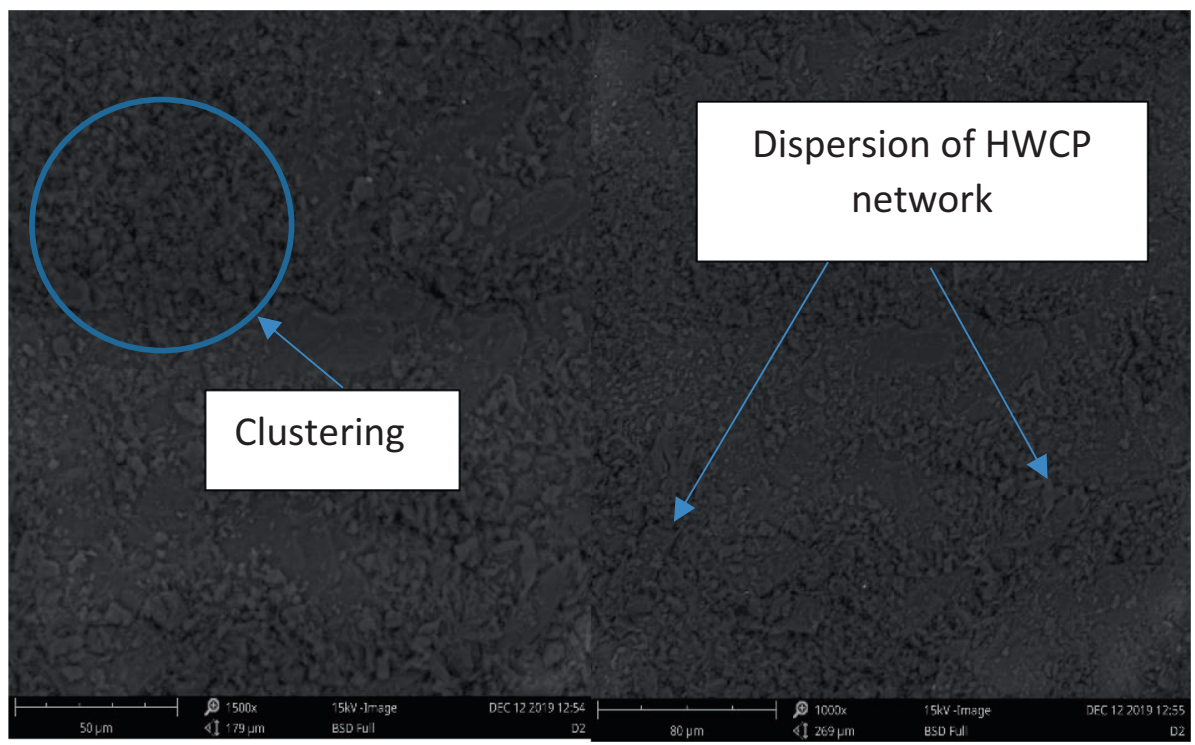

Fig. 6. SEM micrograph of $300 \mu \mathrm{m}$ and $10 \mathrm{wt} \%$ particulate charcoal reinforced polyester matrix composite scanned at different magnifications.

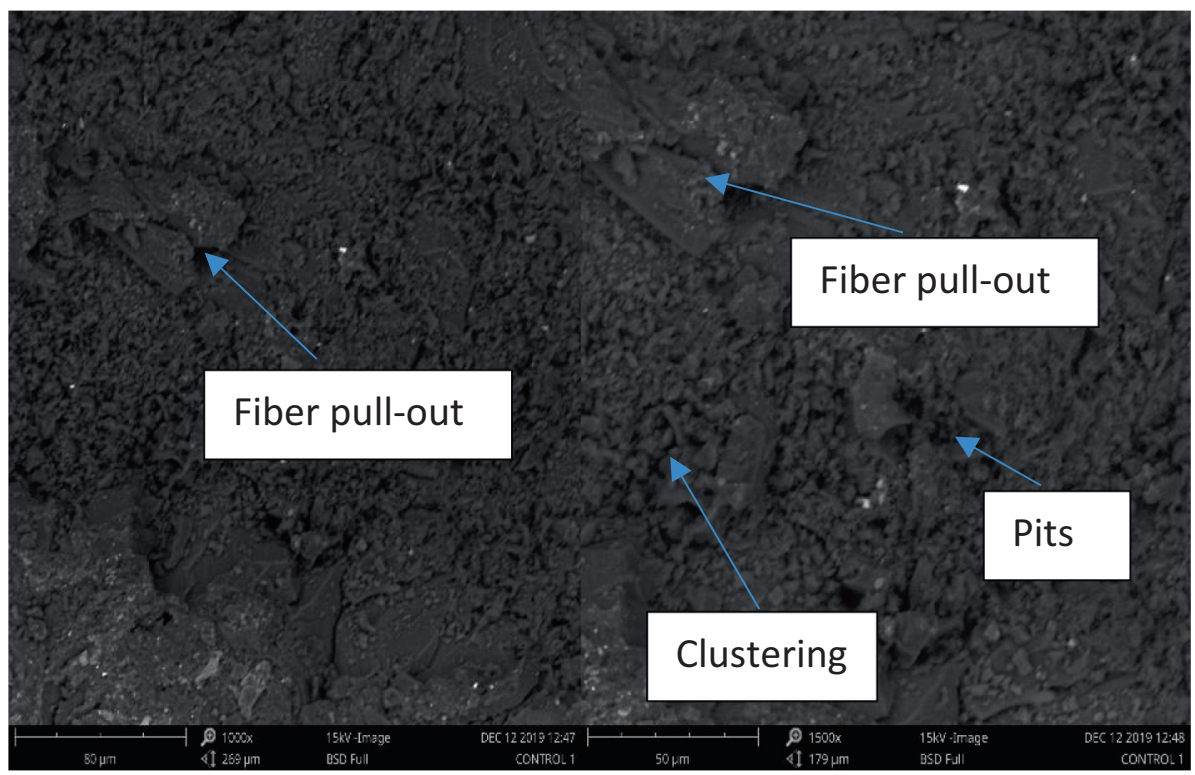

Fig. 7. SEM micrograph of the unreinforced polyester matrix scanned at different magnifications.

\subsection{Impact energy}

The influence of reinforcement content and particle sizes on the impact energy absorbed by the composites during fracture are plotted in Fig. 1. The curve plots in Fig. 1, for both the hardwood charcoal particle reinforced and unreinforced polyester resin matrix composites depict a continuous increase of the impact energy with an increase in the reinforcement particle sizes up to the $15 \mathrm{wt} \%$ reinforcement concentration. The $300 \mu \mathrm{m}$ particle generally absorbed more impact energy, while the $250 \mu \mathrm{m}$ have higher impact energy at low reinforcement weight fraction. The maximum impact energy absorbed before fracture was 5.77 Joules by the $300 \mu \mathrm{m}$ particle size at $15 \mathrm{wt} \%$ filler content, showing a $14.7 \%$ increase in impact energy. The magnitude of the impact energy of the plotted curve for the reinforced polyester resin composites is higher than that for the unreinforced polyester resin composites for the $300 \mu \mathrm{m}$ reinforcement. This increase of impact energy of the $\mathrm{HWCP} /$ polyester composite at $300 \mu \mathrm{m}$ and higher reinforcement concentrations could be interpreted to be as a result of the ability of the large reinforcement particles to block the crack propagation sites [13]. While, the hardwood charcoal powder induced a little reduction in impact energy of the reinforced polyester for the 75 , 150 and $250 \mu \mathrm{m}$ particle sizes [15]. This decrease in impact energy by the 75,150 and $250 \mu \mathrm{m}$ particle sizes may also be interpreted to be due to decrease in the elasticity of the composites and decreased deformability of the matrix phase. As the reinforcement content increases, there is poor interfacial interaction and adhesion/bonding between the polyester matrix and the HWCP giving rise to the formation of micro-cracks and stress concentration sites at the point of impact which required less energy to initiate and propagate cracks in the composites and thereby lowering the amount of impact energy absorbed to fracture [17,18]. 


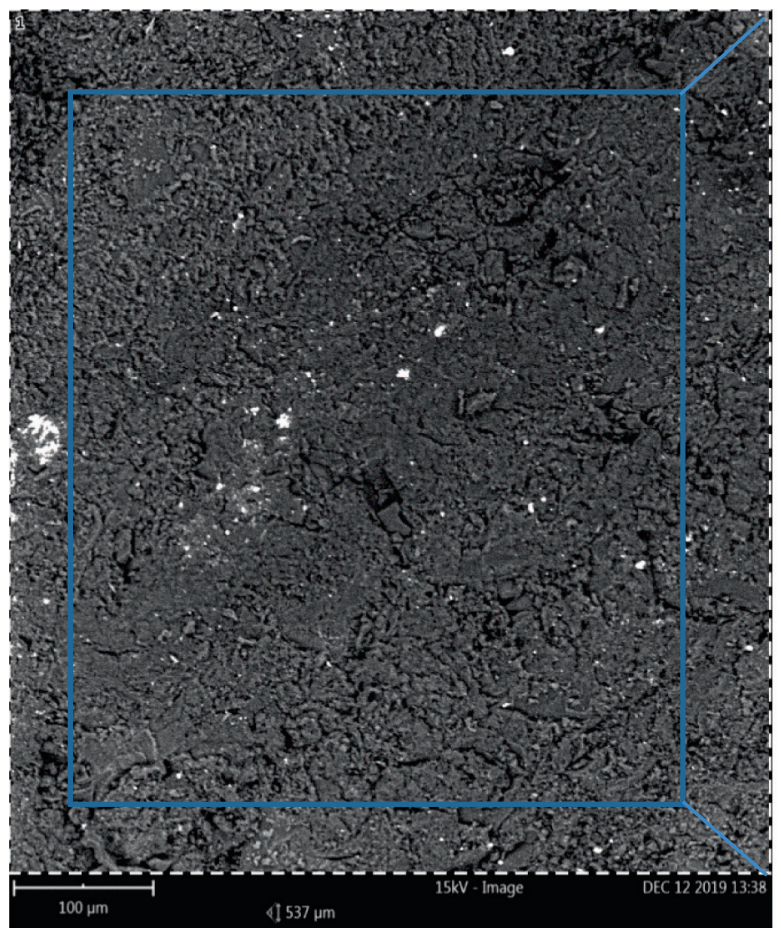

\begin{tabular}{lll}
\hline $\begin{array}{l}\text { Element } \\
\text { Symbol }\end{array}$ & $\begin{array}{l}\text { At. } \\
\text { Conc. }\end{array}$ & $\begin{array}{l}\text { Wt. } \\
\text { Conc. }\end{array}$ \\
\hline $\mathrm{C}$ & 93.01 & 78.97 \\
$\mathrm{Ag}$ & 0.97 & 7.41 \\
$\mathrm{Ca}$ & 0.87 & 2.47 \\
$\mathrm{Si}$ & 1.19 & 2.36 \\
$\mathrm{~K}$ & 0.77 & 2.13 \\
$\mathrm{Cl}$ & 0.69 & 1.72 \\
$\mathrm{Al}$ & 0.88 & 1.68 \\
$\mathrm{P}$ & 0.53 & 1.16 \\
$\mathrm{~S}$ & 0.47 & 1.06 \\
$\mathrm{Mg}$ & 0.30 & 0.52 \\
$\mathrm{Na}$ & 0.32 & 0.51 \\
\hline
\end{tabular}

Fig. 8. SEM-EDX result of polyester matrix composite reinforced with $10 \mathrm{wt} \%$ of $75 \mu \mathrm{m}$ particulate charcoal.

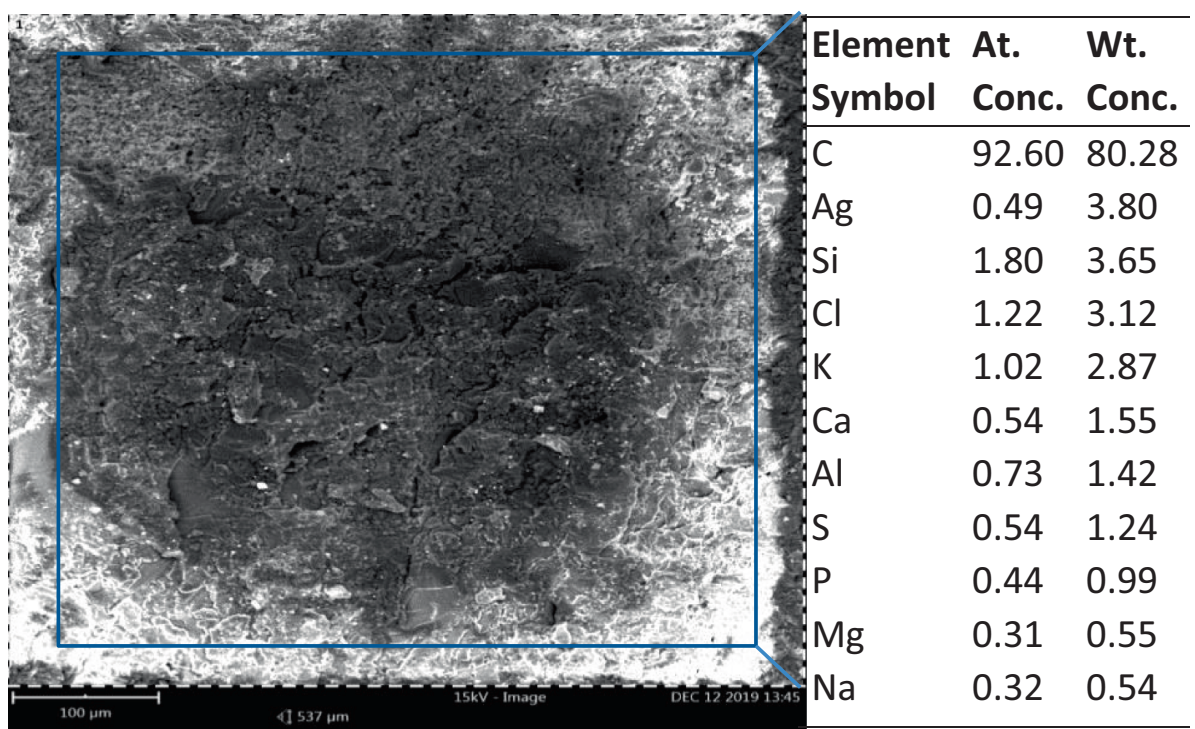

Fig. 9. SEM-EDX result of the unreinforced polyester matrix.

\subsection{Hardness}

The values of hardness presented in Table 1 are used to plot the graph in Fig. 2, showing the effect of HWCP concentration (\% weight fraction) and particle sizes $(\mu \mathrm{m})$ on the hardness values of the HWCP/polyester matrix composites. From Fig. 2, it is clear that the charcoal/polyester composites have higher hardness values at $75,150 \& 250 \mu \mathrm{m}$ particle sizes and increases with increase in the weight fraction of the reinforcement incorporated in the polyester matrix. Maximum hardness value of $54.1 \mathrm{HBW}$ was obtained for the $150 \mu \mathrm{m}$ particle size at $20 \%$ reinforcement weight fraction. This agrees with the conclusion of other research findings, that the reinforcement concentration and particle sizes significantly affect the hardness of composites materials, as hardness increases with increase in the reinforcement content of particulate reinforced composites and reduces with increasing particle sizes [13]. This is because at lower particle sizes and relative reinforcement concentrations (5-20 wt\%) the particles could be dispersed evenly in the polyester matrix without bunching. The increase in hardness might as well be related to the microstructure of the composites and nature of the reinforcement $[13,19]$. As revealed by the EDX result of the $\mathrm{HWCP} /$ polyester matrix composite, the reinforced polyester composites contain more concentrations of silicon, calcium and potassium, which could have enhanced the hardness of the composites. In addition, wood charcoal particles have countless number of small pores in its structure, and these holes created 
room for stronger interface between the filler and the polyester matrix $[15,20]$. The polyester resin matrix embedded into the pores of HWCP and held the particles tightly together as binder, as the increased surface area and porous structure of the HWCP allow the polyester matrix to infiltrate into the pores of the HWCP to develop strong interfacial interactions and physical/mechanical interlocking [20]. Although this interlocking structure could also be observed for larger particle sizes and high concentrations of the HWCP, the quantity of the polyester resin that embedded into the pores of HWCP were very low, leading to a weakened interlocking of composites and bonding effect of the polyester resin. Hence, the decrease in the hardness values for the $300 \mu \mathrm{m}$ HWCP reinforced polyester composites [18]. The $300 \mu \mathrm{m}$ reinforcement particle size exhibited hardness values lower than that of the control sample (unreinforced polyester matrix) at lower reinforcement concentrations ( 10 \& $15 \mathrm{wt} \%$ ).

\subsection{Scanning electron microscopy (SEM) and energy dispersive X-ray spectroscopy (EDX) results}

The unreinforced and reinforced polyester matrix composites were subjected to scanning electron microscopy examination with the resulting images/surface morphologies shown in Figs. 3-7. The corresponding EDX elemental characterization of the reinforced and unreinforced polyester composites chemical compositions is depicted in Figs. 8 \& 9.

The SEM micrograph in Figs. 3-6 show that the reinforcement particles were evenly dispersed in the polyester matrix and the images have more surface roughness than the unreinforced polyester (Fig. 7), arising from the presence of the particles of hardwood charcoal. Moreover, the polymer chains were embedded into the channels of hardwood charcoal and strong interfacial interaction was achieved between charcoal particles and polyester matrix so that charcoal powder and polymer resin could combine tightly to each other. The EDX results characterized electronically (Fig. 8 \& 9) revealed the presence of carbon, silver, calcium, silicon and potassium as major elements with increased concentrations of calcium, silicon, potassium and aluminium in the HWCP reinforced composites.

\section{Conclusions}

The following conclusions were made:

The charcoal/polyester composites have higher hardness values at $75,150 \& 250 \mu \mathrm{m}$ particle sizes and increases with increase in the weight fraction of the reinforcement incorporated in the polyester matrix. Maximum hardness value of $54.1 \mathrm{HBW}$ was obtained for the $150 \mu \mathrm{m}$ particle size at $20 \%$ reinforcement weight fraction.

The impact energy of the reinforced polyester matrix composites increased with increase in the particle size and particle weight fraction, as the $300 \mu \mathrm{m}$ hardwood charcoal powder reinforced polyester matrix composites absorbed more impact energy before fracture.

The EDX results indicated an increase in the contents of calcium, silicon, potassium and aluminium in the reinforced polyester matrix composites. SEM image show the homogeneous distribution of the reinforcement particles in the majorly carbon matrix phase and increased surface roughness of the reinforced polyester matrix composites.

In general, the addition of hardwood charcoal reinforcement leads to an improvement in the impact, hardness and structure of the polyester resin.

\section{CRediT authorship contribution statement}

R.O. Akaluzia: Supervision, Conceptualization, Methodology, Software. F.O. Edoziuno: Conceptualization, Data curation, Writing - original draft. A.A. Adediran: Data curation, Writing - review \& editing. B.U. Odoni: Visualization, Investigation. S. Edibo: Writing - review \& editing. T.M.A. Olayanju: Software, Validation.

\section{Declaration of Competing Interest}

The authors declare that they have no known competing financial interests or personal relationships that could have appeared to influence the work reported in this paper.

\section{Acknowledgments}

The Tertiary Education Trust Fund (TETFund), Nigeria through the Institution Based Research (IBR) Interventions, financially supported this research.

\section{References}

[1] F.C. Campbell, Introduction to composite materials, in: Struct. Compos. Mater., ASM International, 2010:1-10. www.asminternational.org.

[2] P.K. Saha, Introduction to composite materials for aerospace, Aerosp. Manuf. Process. (2016) 127-157, https://doi.org/10.1201/9781315367965-6.

[3] O.O. Daramola, A.D. Akinwekomi, A.A. Adediran, O. Akindote-White, E.R. Sadiku, Mechanical performance and water uptake behaviour of treated bamboo fibre-reinforced high-density polyethylene composites, Heliyon 5 (7) (2019) e02028.

[4] A.V. Ratna Prasad, K. Mohana Rao, Mechanical properties of natural fibre reinforced polyester composites: jowar, sisal and bamboo, Mater. Des. 32 (2011) 4658-4663, https://doi.org/10.1016/j.matdes.2011.03.015.

[5] I.O. Oladele, I.O. Ibrahim, A.A. Adediran, A.D. Akinwekomi, Y.V. Adetula, T.M.A. Olayanju, Modified palm kernel shell fiber/particulate cassava peel hybrid reinforced epoxy composites, Results Mater. 5 (2020) 100053.

[6] M. Sakthivei, S. Ramesh, Mechanical properties of natural fibre (Banana, Coir, Sisal) polymer composites, Sci. Park. 1 (2013).

[7] W.A. Shakir, M.R. Mohammed, I.H. Hilal, Mechanical characteristics of (TiO 2ZnO)/PMMA nanocomposites for dentures, Int. J. Med. Res. Heal. Sci. 8 (2019) 59-72.

[8] K. Srinivas, A. Lakshumu Naidu, M.V.A. Raju, Bahubalendruni, A review on chemical and mechanical properties of natural fiber reinforced polymer composites, Int. J. Performability Eng. 13 (2017) 189-200.

[9] U. Sudhakar, B.V. Suresh, M.V.A.R. Bahubalendruni, A review on physical and chemical properties of natural fiber reinforced composite materials, Int. J. Sci. Dev. Res. 3 (2018) 160-172.

[10] J.O. Akindapo, E.T. Agov, D.K. Garba, R.O. Ogabi, Comparative assessment of mechanical properties of groundnut shell and rice husk reinforced epoxy composites, Am. J. Mech. Eng. 5 (2017) 76-86, https://doi.org/10.12691/ajme5-3-2.

[11] N. Venkateshwaran, A. ElayaPerumal, A. Alavudeen, M. Thiruchitrambalam, Mechanical and water absorption behaviour of banana/sisal reinforced hybrid composites, Mater. Des. 32 (2011) 4017-4021, https://doi.org/10.1016/ j.matdes.2011.03.002.

[12] V. Jagadeesh, K. Venkatasubbaiah, A.L. Naidu, Experimental study on mechanical behavior of natural hybrid composites filled with ground nut shell ash, Mech. Mech. Eng. 23 (2019) 218-227, https://doi.org/10.2478/mme2019-0029.

[13] S.A. Kolawole, A. Danladi, B.M. Dauda, U.S. Ishiaku, Effects of particle size on the physico-mechanical properties of epoxy filled with dates palm pits (Phoenix dactylifera) particulate composites, Direct Res. J. Chem. Mater. Sci. 6 (2019) 14-24. https://doi.org/https://doi.org/10.5281/zenodo.3371077.

[14] V. Rambabu, S. Kona, A.L. Naidu, P.R. Rao, Mechanical properties of okra and jute fibers filled with groundnut shell ash reinforced composites with epoxy (LY556) and epoxy (XIN 100 IN) resin matrices, J. Mater. Environ. Sci. 9 (2018) 2169-2173.

[15] S. Li, X. Li, Q. Deng, D. Li, Three kinds of charcoal powder reinforced ultra-high molecular weight polyethylene composites with excellent mechanical and electrical properties, Mater. Des. 85 (2015) 54-59, https://doi.org/10.1016/ j.matdes.2015.06.163.

[16] W. Webo, L. Masu, M. Maringa, The impact toughness and hardness of treated and untreated sisal fibre-epoxy resin composites, Adv. Mater. Sci. Eng. (2018), https://doi.org/10.1155/2018/8234106.

[17] C.I. Madueke, B. Bolasodun, R. Umunakwe, J.N. Nwonah, Comparison of the mechanical properties of charcoal unsaturated polyester matrix composite and snail shell unsaturated polyester matrix composite, Int. J. Sci. Eng. Res. 5 (2014) 208-213. 
[18] Q. Zhang, M. Usman, X. Lin, H. Cai, H. Lei, Temperature varied biochar as a reinforcing filler for high-density polyethylene composites, Compos. Part B. 175 (2019), https://doi.org/10.1016/j.compositesb.2019.107151 107151.

[19] J.R.M.D. Almeida, B.H.P. Manfredini, Hardness evaluation of epoxy resin filled with mineral waste, J. Appl. Polym. Sci. 84 (2002) 2178-2184, https://doi.org/ 10.1002/app.10488.
[20] X. Li, B. Lei, Z. Lin, L. Huang, S. Tan, X. Cai, The utilization of bamboo charcoal enhances wood plastic composites with excellent mechanical and thermal properties, J. Mater. Des. (2013), https://doi.org/10.1016/

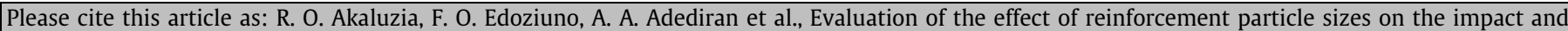

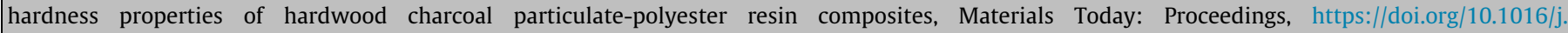
matpr.2020.02.980 